AMR Centre, London School of Hygiene and Tropical Medicine, London, UK

2 University College London Hospitals NHS Trust, London, UK

3 Department of Specialist Allergy and Clinical Immunology, University College London Hospitals, London, UK

4 Division of Rheumatology, Allergy, and Immunology, Massachusetts General Hospital, Harvard Medical School, Boston, MA, USA

Correspondence to: RE Glover rebecca.glover@lshtm.ac.uk Cite this as: BMJ 2021;372:n120 http://dx.doi.org/10.1136/bmi.n120 Published: 18 January 2021

\section{Vaccinating against covid-19 in people who report allergies}

\author{
Most patients can be reassured and vaccinated \\ Rebecca E Glover, ${ }^{1}$ Robert Urquhart, ${ }^{2}$ Joanna Lukawska, ${ }^{3}$ Kimberly G Blumenthal ${ }^{4}$
}

Use of the Pfizer-BioNTech covid-19 vaccine in people with a history of severe allergies was temporarily stopped in the UK after two healthcare workers experienced anaphylactic reactions in early December. The Medicines and Healthcare Products Regulatory Agency (MHRA) stated that "any person with a history of anaphylaxis to a vaccine, medicine, or food should not receive the Pfizer/BioNTech vaccine." 1

However, MHRA revised its position on 30 December after careful consideration based on enhanced surveillance of over one million doses of the vaccine in the UK and North America-including in jurisdictions where people with serious allergies were never barred from receiving the vaccine. ${ }^{2}$ It found no evidence of an increased risk of anaphylaxis to the Pfizer-BioNTech vaccine among people with serious but unrelated allergy histories and advised that only people who had an allergic reaction to the first dose of this vaccine, or who previously had reactions to any of its components, should not receive it.

This is welcome news for people with severe allergies, but risks to the UK rollout of covid-19 vaccines remain because of the widespread dissemination of the allergy contraindication in the media. Front page headlines in the New York Times and on CNN and the BBC all outlined vaccine risks to people with allergies. ${ }^{3-5}$ However, MHRA's revised guidance received little media coverage. The reporting of allergy as synonymous with anaphylaxis is concerning, since in the UK and US $20-40 \%$ of the population has at least one allergic disease, ${ }^{6-9}$ an umbrella term for multiple clinical syndromes (allergic rhinitis, anaphylaxis, allergic asthma, conjunctivitis, eczema and contact dermatitis, food allergy, and urticaria) caused by food, aeroallergens (including pollen), and immunologically mediated adverse effects of medicines. ${ }^{6}$

Before the Pfizer-BioNTech vaccine contraindication was announced, surveys reported that the public's willingness to be vaccinated with one of the new covid-19 vaccines ranged from $67 \%$ to $90 \%$. $^{10}$ That estimate has been fluctuating, however. In one study conducted from April to May 2020, 90\% of parents and guardians of young children said they would accept a novel covid-19 vaccine, ${ }^{11}$ while in June, a similar questionnaire reported potential uptake to be roughly $70 \% .{ }^{12}$ By July 2020, another UK study found that $64 \%$ of participants were "very likely" to accept a covid-19 vaccine, with another $27 \%$ unsure. ${ }^{13}$ Vaccine hesitancy seems to be highest in ethnic minority populations. ${ }^{10}$

Given that allergies are commonly reported, and public acceptance for a covid-19 vaccine seems to be waning, uptake of the Pfizer-BioNTech vaccine may be lower than hoped, particularly among patients with allergies. This may lead to covid-19 outbreaks, necessitating local lockdowns and hampering pandemic responses. Healthcare workers may also be reluctant to vaccinate people with any history of allergies. It is therefore essential that those planning and administering covid-19 vaccine programmes understand the evidence.

\section{Key facts}

Importantly, history of severe allergy does not preclude vaccination unless that allergy is to the vaccine or its components. Only one of the excipients in the Pfizer-BioNTech vaccine is a known potential allergen, polyethylene glycol (PEG 2000), and this is an inactive ingredient in over 1000 medications. The Oxford-AstraZeneca vaccine does not contain PEG 2000 so remains an alternative for people with a history of allergy to this ingredient. ${ }^{2}$ However, there is some cross-reactivity between PEG and polysorbate 80 , an ingredient in the Oxford-AstraZeneca vaccine, so evaluation by an allergy specialist may be advisable before vaccination in anyone with a suspected PEG allergy history. ${ }^{14}$ Allergy is antigen specific, although people with one drug allergy may be more susceptible to other drug allergies than the general population. ${ }^{15}$

And finally, the best approaches to vaccine hesitancy include "science, education, access, civil discourse, and debate," ${ }^{16}$ not coercion or censorship. Vaccinators should be prepared to provide information, explain the difference between severe, moderate, and mild allergies, and clarify MHRA's decision making. People's views about covid vaccines may transfer to other vaccines- such as regular immunisation for themselves and their families-and future vaccines, so maintain open lines of communication, and if vaccination is declined, then reassure people that they can return.

It may still be possible to safely vaccinate people with allergies to vaccine components. ${ }^{17}$ Allergists can assess patients who report allergy to a vaccine, injectable medication, or PEG and triage them into those able to go ahead with vaccination with the routine 15 minutes of observation, those requiring 30 minutes of observation, and those who require skin testing to PEG and polysorbate before vaccination. Our hospitals have already launched such services and evaluation is ongoing.

Competing interests: The BM/has judged that there are no disqualifying financia ties to commercial companies. The authors declare no other interests. The BMJ policy on financial interests is here: https://www.bmj.com/sites/default/files/attachments/resources/2016/03/16-current-bmj-education-coi-form.pdf.

Provenance and peer review: Commissioned; not externally peer reviewed. 
1 Raine J. Confirmation of guidance to vaccination centres on managing allergic reactions following COVID-19 vaccination with the Pfizer/BioNTech vaccine. MHRA press release, 9 Dec 2020. https://www.gov.uk/government/news/confirmation-of-guidance-to-vaccination-centres-onmanaging-allergic-reactions-following-covid-19-vaccination-with-the-pfizer-biontech-vaccine

2 BSACI. Update on MHRA decision re: Pfizer covid-19 vaccination 30.12.20. 2020. https://www.bsaci.org/update-on-mhra-decision-re-pfizer-covid-19-vaccination/

3 Reynolds E, Braithwaite S, Cassidy A. Allergy warning for Pfizer/BioNTech vaccine after UK health workers with allergy history suffer reaction. CNN2020 Dec 10. https://edition.cnn.com/2020/12/09/health/covid-vaccine-allergies-health-workers-uk-intl-gbr/index.html

4 Grady D. Pfizer's covid vaccine and allergies: how concerned should you be? New York Times 2020 Dec 11. https://www.nytimes.com/2020/12/11/health/Covid-Pfizer-vaccine-allergies.html

5 Triggle N, Schraer R. Covid-19 vaccine: allergy warning over new jab. BBC News 2020 Dec 10. https://www.bbc.co.uk/news/health-55244122

6 Anandan C, Gupta R, Simpson CR, Fischbacher C, Sheikh A. Epidemiology and disease burden from allergic disease in Scotland: analyses of national databases. J R Soc Med 2009;102:431-42. doi: 10.1258/irsm.2009.090027 pmid: 19797601

7 Gupta R, Sheikh A, Strachan DP, Anderson HR. Time trends in allergic disorders in the UK. Thorax 2007;62:91-6. doi: 10.1136/thx.2004.038844 pmid: 16950836

8 Gupta R, Sheikh A, Strachan DP, Anderson HR. Burden of allergic disease in the UK: secondary analyses of national databases. Clin Exp Allergy 2004;34:520-6. doi: 10.1111/j.1365-2222.2004.1935.x pmid: 15080802

9 Blumenthal KG, Peter JG, Trubiano JA, Phillips E). Antibiotic allergy. Lancet 2019;393:183-98. doi: 10.1016/S0140-6736(18)32218-9 pmid: 30558872

10 Paterson P. Will the public accept a covid-19 vaccine? BMJ Opinion, 13 Nov 2020. https://blogs.bmj.com/bmi/2020/11/13/pauline-paterson-will-the-public-accept-a-covid-19-vaccine/

11 Bell S, Clarke R, Mounier-Jack S, Walker IL, Paterson P. Parents' and guardians' views on the acceptability of a future covid-19 vaccine: a multi-methods study in England. Vaccine 2020;38:7789-98. doi: 10.1016/j.vaccine.2020.10.027 pmid: 33109389

12 Lazarus JV, Ratzan SC, Palayew A, etal. A global survey of potential acceptance of a COVID-19 vaccine. Nat Med 2020. [Epub ahead of print.] . doi: 10.1038/s41591-020-1124-9 pmid: 33082575

13 Sherman SM, Smith LE, Sim J, etal. COVID-19 vaccination intention in the UK: results from the COVID-19 vaccination acceptability study (CoVAccS), a nationally representative cross-sectional survey. Hum Vaccin Immunother 2020; 1-10; Epub ahead of print. doi: 10.1080/21645515.2020.1846397 pmid: 33242386

14 Stone CA, JLLiu Y, Relling MV, etal. Immediate hypersensitivity to polyethylene glycols and polysorbates: more common than we have recognized. J Allergy Clin Immunol Pract 2019;7:1533-1540.e8. doi: 10.1016/j.jaip.2018.12.003 pmid: 30557713

15 Blumenthal KG, Li Y, Acker WW, etal. Multiple drug intolerance syndrome and multiple drug allergy syndrome: Epidemiology and associations with anxiety and depression. Allergy 2018;73:2012-23. doi: 10.1111/all.13440 pmid: 29574787

16 Godlee F. What should we do about vaccine hesitancy?BM/2019;365:1404/4doi: 10.1136/bmj.14044

17 Sharma K, Perrett KP, Wood N. Yellow fever vaccination in egg-allergic children. Pediatr Infect Dis /2020;39:e76-8. doi: 10.1097/INF.0000000000002625 pmid: 32118856

This article is made freely available for use in accordance with BMJ's website terms and conditions for the duration of the covid-19 pandemic or until otherwise determined by BMJ. You may use, download and print the article for any lawful, non-commercial purpose (including text and data mining) provided that all copyright notices and trade marks are retained. 